UCRL-JC-125873

PREPRINT

\title{
A Low-Profile High-Voltage Compact Gas Switch
}

\author{
David A. Goerz \\ Michael J. Wilson \\ Ronnie D. Speer
}

This paper was prepared for submittal to the 11th Institute for Electrical and Electronics Engineers

International Pulsed Power Conference

Baltimore, MD

June 29 - July 2, 1997

June 30, 1997

This is a preprint of a paper intended for publication in a journal or proceedinga. Since changes may be made before publication, this preprint is made available with the understanding that it will not be cited or reproduced without the permiseion of the author. 


\section{DISCLAIMER}

This document was prepared as an account of work sponsored by an agency of the United States Government. Neither the United States Government nor the University of California nor any of their employees, makes any warranty, express or implied, or assumes any legal liability or responsibility for the accuracy, completeness, or usefulness of any information, apparatus, product, or process

disclosed, or represents that its use would not infringe privately owned rights. Reference herein to any specific commercial product, process, or service by trade name, trademark, manufacturer, or otherwise, does not necessarily constitute or imply its endorsement, recommendation, or favoring by the United States Government or the University of California. The views and opinions of authors expressed herein do not necessarily state or reflect those of the United States Government or the University of California, and shall not be used for advertising or product endorsement purposes. 


\title{
A LOW-PROFILE HIGH-VOLTAGE COMPACT GAS SWITCH ${ }^{*, 1}$
}

\author{
D. A. Goerz, M. J. Wilson, and R. D. Speer \\ Lawrence Livermore National Laboratory \\ P. O. Box 808 (L-153) \\ Livermore, CA $94550-9900$
}

\begin{abstract}
This paper discusses the development and testing of a low-profile, high-voltage, spark-gap switch designed to be closely coupled with other components into an integrated high-energy pulsed-power source. The switch is designed to operate at 100 $\mathrm{kV}$ using $\mathrm{SF}_{6}$ gas pressurized to less than $0.7 \mathrm{MPa}$. The volume of the switch cavity region is less than $1.5 \mathrm{~cm}^{3}$, and the field stress along the gas-dielectric interface is as high as $130 \mathrm{kV} / \mathrm{cm}$. The dielectric switch body has a low profile that is only $1-\mathrm{cm}$ tall at its greatest extent and nominally $2-\mathrm{mm}$ thick over most of its area. This design achieves a very low inductance of less than $5 \mathrm{nH}$, but results in field stresses exceeding 500 $\mathrm{kV} / \mathrm{cm}$ in the dielectric material. Field modeling was done to determine the appropriate shape for the highly stressed insulator and electrodes, and special manufacturing techniques were employed to mitigate the usual mechanisms that induce breakdown and failure in solid dielectrics. Static breakdown tests verified that the switch operates satisfactorily at $100 \mathrm{kV}$ levels. The unit has been characterized with different shaped electrodes having nominal gap spacings of $2.0,2.5$, and $3.0 \mathrm{~mm}$. The relationship between self-break voltage and operating pressure agrees well with published data on gas properties, accounting for the field enhancements of the electrode shapes being used. Capacitor discharge tests in a low inductance test fixture exhibited peak currents up to $25 \mathrm{kA}$ with characteristic frequencies of the ringdown circuit ranging from 10 to $20 \mathrm{MHz}$. The ringdown waveforms and scaling of measured parameters agree well with circuit modeling of the switch and test fixture. Repetitive operation has been demonstrated at moderate rep-rates up to $15 \mathrm{~Hz}$, limited by the power supply being used. Preliminary tests to evaluate lifetime of the compact switch assembly have been encouraging. In one case, after more than 7,000 high-current ringdown tests with approximately $30 \mathrm{C}$ of total charge transferred, the switch continued to operate satisfactorily with no apparent tracking or deterioration of the insulator.
\end{abstract}

Introduction

Spark gap switches are commonly used in trigger generators, pulse forming networks, Marx generators, and other high-energy pulsed-power systems. They are particularly well suited for applications that require switching of very high voltages and rather high currents.

Marx-type high-voltage generators most frequently use spark gap switches. In principle, Marx generators are simple, and their performance is mainly determined by the basic capacitors and switches that make up each stage. In most applications, Marx generators are constructed with standard, commercially available components that are arranged in an orderly manner into compact assemblies. Since these components are made for general use, their packaging and terminal styles are usually less than optimal for achieving maximum performance and the compactness needed for some applications. Significant improvements can be realized by modifying standard components or by manufacturing special components to fit into integrated packages.

We have developed a design for a repetitively-switched, Marx-type high-voltage generator based on custom components that can be closely coupled and integrated into an extremely compact assembly. ${ }^{1}$ This ultra-compact Marx (UCM) can be used in a variety of special

* Work performed under the auspices of the U. S. Department of Energy by the Lawrence Livermore National Laboratory under Contract W-7405-Eng-48. 
applications requiring a compact high-voltage pulsed-power source. The concept relies on a low-profile, low-inductance, high-voltage, spark-gap switch.

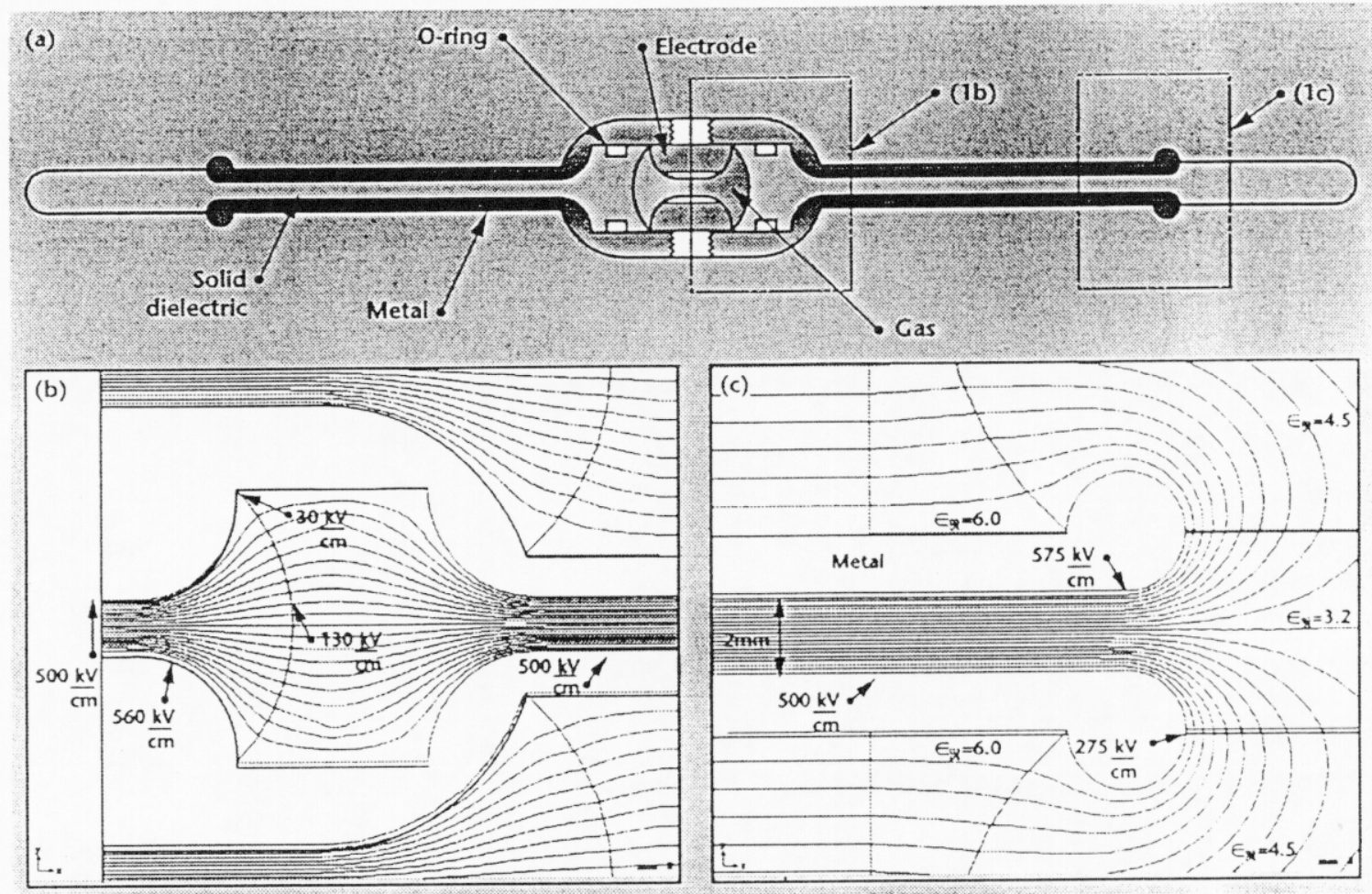

Figure 1. (a) Schematic of compact gas switch; (b) and (c) show field modeling results

\section{Switch Design}

We evaluated many design options and performed field modeling to evaluate the electrical stresses and quantify field enhancements of different shaped assemblies. Through an iterative process, we identified the limiting features and devised suitable design and construction methods to satisfy the basic requirements. Figure $1 \mathrm{a}$ is a sketch of the compact gas switch.

The shape of the metallic and dielectric parts is crucial to properly manage the electric fields and keep the stresses below the threshold for flashover or breakdown of a material. Figures $1 \mathrm{~b}$ and $1 \mathrm{c}$ show field modeling results where contours of equipotential lines are plotted. The metal electrodes and insulator surfaces have been appropriately shaped to reduce electric field stresses in the weakest regions where dissimilar materials meet, and to spread the fields evenly throughout the dielectric materials, allowing them to operate closer to their intrinsic breakdown levels.

Figure $1 \mathrm{~b}$ shows that for the chosen dimensions with an applied voltage of $100 \mathrm{kV}$, the electric field is less than $30 \mathrm{kV} / \mathrm{cm}$ at the triple-point region, and is less than $130 \mathrm{kV} / \mathrm{cm}$ along the envelope of plastic material containing the pressurized gas. These stress levels are below the thresholds reported by others as troublesome. 2,3 The average field across the thinnest annular region of plastic is $500 \mathrm{kV} / \mathrm{cm}$, whereas the highest field at the outermost field-enhanced region is $575 \mathrm{kV} / \mathrm{cm}$.

The gap between the cathode and anode electrodes is sized according to the desired operating level and gas pressure for a particular gas species or mixture. A nominal gap of 2.0 $\mathrm{mm}$ will normally break down at $100 \mathrm{kV}$ with $\mathrm{SF}_{6}$ pressurized to $100 \mathrm{psia}$. Field modeling allowed us to correct the empirical relationship for gas breakdown of planar gaps by including the effect of field enhancement at the edges. As evident in Fig. 1b, the fields are enhanced along the radiused edge of the switch electrodes, reaching $560 \mathrm{kV} / \mathrm{cm}$. This results in an enhancement factor ( $\left.f^{\star}\right)$ of 1.120 , given by the ratio of $560 \mathrm{kV} / \mathrm{cm}$ to $500 \mathrm{kV} / \mathrm{cm} .4$ 
Test Apparatus

We constructed a special test fixture to evaluate various switches and demonstrate their performance over the desired range of operating parameters. Figure 2 is a photograph of the assembled unit. The slotted metal cylinder is the outer current return path for performing current ringdown tests. The finned cylindrical structure below the test fixture is a highenergy current-viewing resistor used as a diagnostic. Figure 3 is a photograph of the components to be evaluated before assembly inside the test fixture. The photo shows a 2-mm-thick switch body nestled between two surrogate annular capacitors. The portion of the switch body that can be seen is $5-\mathrm{mm}$ thick and extends about $2.0 \mathrm{~cm}$ beyond the outer radius of the capacitor electrodes. The capacitor assemblies are constructed of eight ceramic capacitors mounted in a ring around a gas sealed cylindrical insulator.

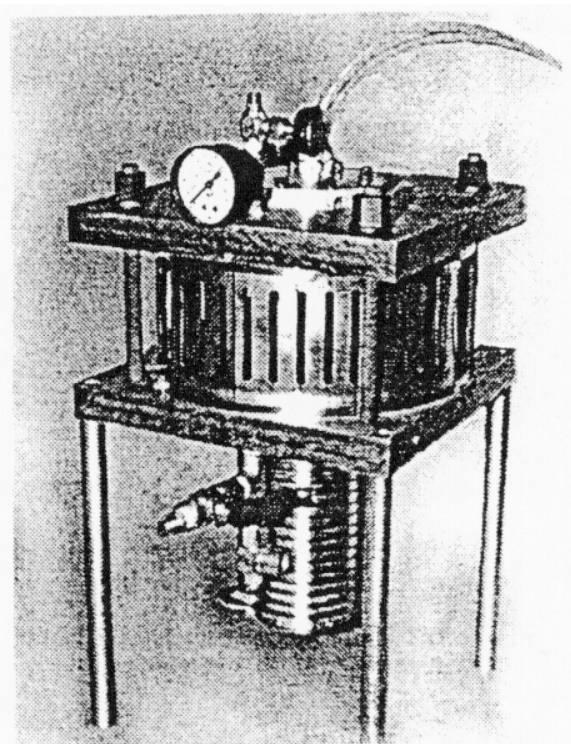

Figure 2. Photograph of test fixture

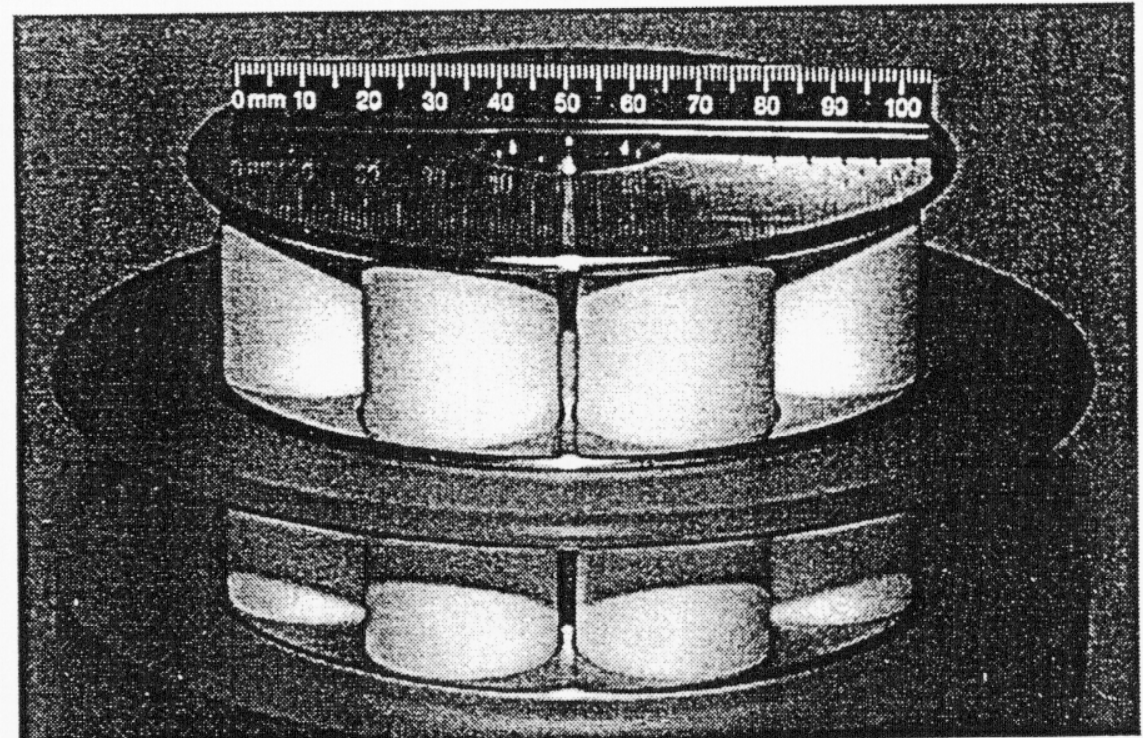

Figure 3. Photograph of compact gas switch nestled between two capacitor assemblies.

Test Results

Static breakdown tests were performed first to observe the relationship between self-break voltage and operating pressure. Three different sets of electrodes were used to characterize the compact gas switch with nominal gap spacings of $2.0,2.5$, and $3.0 \mathrm{~mm}$. Figure 4 shows results from self-break operation for the $2.5-\mathrm{mm}$ gap with $\mathrm{SF}_{6}$ gas. The triangular-shaped markers represent the breakdown measurements that were made at each pressure increment of $5 \mathrm{psi}$. The open circles and curve fit represent the well-known relationship for breakdown of SF6 gas ${ }^{4}$ accounting for the field enhancements for these particular shaped electrodes.

While there is some statistical variation in the breakdown levels, the general agreement with the empirical model indicates that the switch indeed functions as intended. Considerable testing confirmed that the electric field stress has been properly managed at the triple points and along the insulator surface, and that the switch operates satisfactorily at $100 \mathrm{kV}$ levels. 
Further testing was done to exercise the compact gas switch at desired peak currents and chargetransfer levels. Figure 5 shows the current trace from a typical ringdown event. The peak current of $20 \mathrm{kA}$ is limited mainly by the rather large inductance of the test fixture and capacitors. Subsequent testing with a somewhat lower inductance circuit achieved peak currents as high as $25 \mathrm{kA}$. Figure 6 shows the relationship between peak current and the switch operating voltage. The solid square markers indicate the experimental data points. The open triangular markers and solid curve fit represent analytical estimates of the peak current based on circuit parameters assuming ideal capacitors.



Figure 4. Static breakdown test results

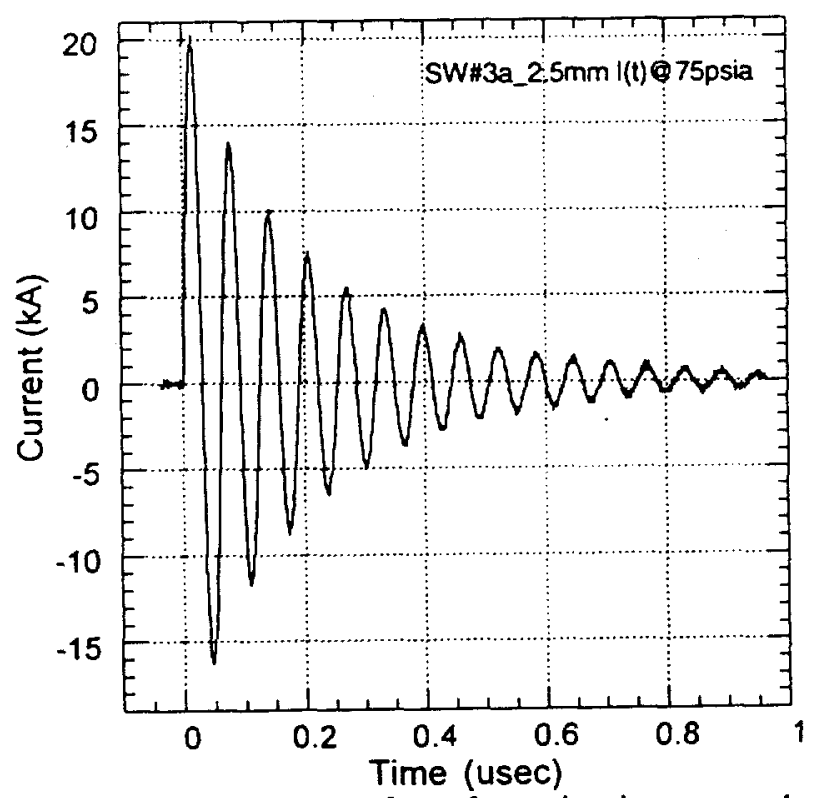

Figure 5. Current waveform from ringdown event

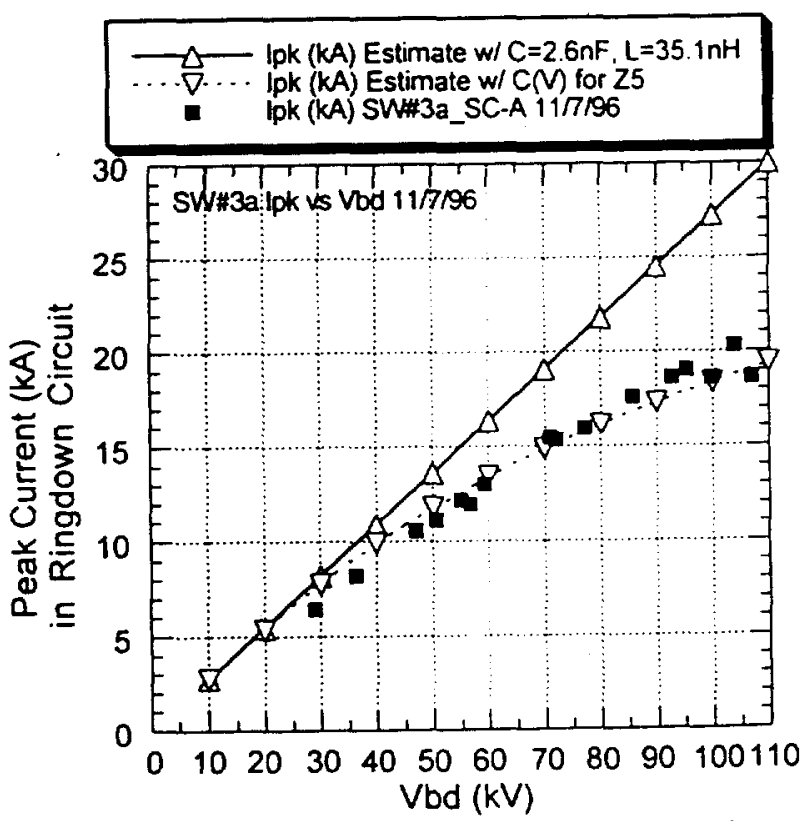

Figure 6. Peak current verses operating voltage

The dashed curve fit in Figure 6 represents the analytical estimates of peak currents using actual values for the capacitors knowing their voltage dependent characteristics. The capacitance of the Z5 ceramic capacitors used in these initial tests is known to fall off severely at higher voltage levels. We performed LCR-bridge measurements at elevated levels to accurately characterize these capacitors. ${ }^{5}$

Next, we performed tests to determine whether the insulator would survive repetitive highenergy pulses, or whether electrode erosion would become troublesome. Figure 7 shows a typical voltage trace from a 4-second burst-mode operation of a 3-mm gap switch with $\mathrm{SF}_{6}$ at 
65 psia and the 100-kV power supply current limited by a 20 $M \Omega$ series resistor.

Considerable testing was done at these moderate rep-rates of 10 to $15 \mathrm{~Hz}$. We anticipate the compact switch will operate satisfactorily at rep-rates up to $50 \mathrm{~Hz}$. This mode of operation was also used to determine the statistical variation of voltage breakdown levels to evaluate how well the switch would function in a Marx-type highvoltage generator.

For the 4-s burst shown in Figure 7 , the mean operating voltage was $88.8 \mathrm{kV}$ and the standard deviation was $4.5 \mathrm{kV}$ or $5.0 \%$. This statistical variation is adequate for a Marx generator to function reliably with a reasonable amount of voltage coupling between stages to ensure successive switch operation.

To evaluate the expected lifetime of such a compact switch assembly, multiple 4-s bursts were taken, and the voltage and ringdown current waveforms were recorded for each shot. The switch still operated satisfactorily after more than 175 bursts, totaling more than 7,000 individual shots. This series of tests ended when one of the capacitors failed.

Figure 8 shows a close-up photograph of the Lexan switch housing. No tracking or deterioration could be seen. After inspection, the switch was reinstalled for further testing.

Most of the electrical testing was done with a polycarbonate material (Lexan). Figure 9 shows a close-up photograph of one switch housing made from an extruded Lexan cylinder. Stress fractures were apparent after machining the inner switch cavity. This particular switch still operated satisfactorily for more than 1,000 shots; however, the crazing became progressively worse.



Figure 8. Photo of tested Lexan switch housing with $1-\mathrm{cm}$ electrode opening



Figure 9. Photo of machined Lexan switch housing with stress fractures 
Several types of insulator materials were used to evaluate machining methods. Switch housings were also manufactured using alumina-trihydrate (ATH) loaded epoxy and EPON-825 thermoset resin. ATH machined very easily, whereas some difficulty was experienced machining the EPON material.

Some information about electrode erosion was gained from these tests. The replaceable button electrodes were weighed before and after the lifetime tests described above. The mass loss was $5.4 \mathrm{mg}$ for each of the cathode and anode electrodes, and the erosion appeared uniformly distributed over the front face of

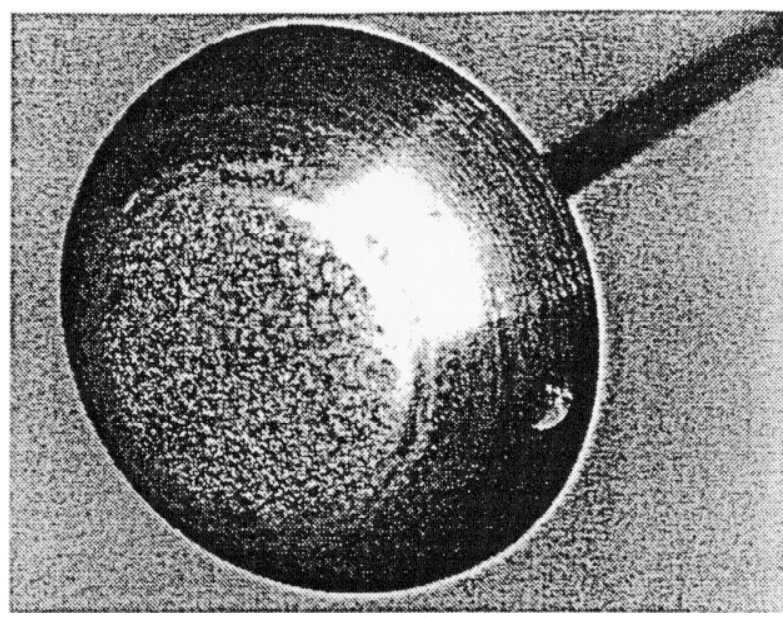

Figure 10. Photograph of button electrode the electrodes as shown in Figure 10. The total charge transferred through the switch during the period in which these electrodes were installed was $30.4 \mathrm{C}$. The specific mass loss amounted to $0.178 \mathrm{mg} / \mathrm{C}$, which is consistent with typical erosion rates reported in the literature. ${ }^{6}$

\section{Summary}

We have developed a low-profile, high-voltage, spark-gap switch designed to be closely coupled with other components into an integrated high-energy pulsed-power source. We performed field modeling to determine the appropriate shape for the highly stressed insulator and electrodes, and employed special manufacturing techniques to mitigate the usual mechanisms that induce breakdown and failure in solid dielectrics 7 . We have constructed and tested a prototype switch unit and achieved satisfactory operation at $100 \mathrm{kV}$ levels. Preliminary tests to evaluate repetitive operation and lifetime have been encouraging.

\section{Acknowledgments}

The authors gratefully acknowledge the contributions of Wang $\mathrm{Ng}$ who performed the field modeling, and Joe Penland who constructed the test apparatus. Many thanks go to Lorna Naugle for clerical support throughout the project and preparation of this manuscript. Funding for this work was provided by LLNL's Power Conversion Technologies Thrust Area led by Mark Newton, and support was provided by LLNL's Computational Electromagnetics Thrust Area led by Cliff Shang.

\section{References}

1. This report contains information included in pending patents: D. A. Goerz, M. J. Wilson, and R. D. Speer, A Low-Profile High-Voltage Compact Gas Switch, 11th IEEE International Pulsed Power Conference, Baltimore, MD, LLNL Doc. UCRL-JC-125873, June 1997.

2. J. R. Laghari, Surface Flashover of Spacers In Compressed Gas Insulated Systems, IEEE Transactions on Electrical Insulation, Vol. El-16 (5) 1981.

3. J. R. Laghari, Spacer Flashover in Compressed Gases, IEEE Transactions on Electrical Insulation, Vol. El-20 (1), 1985.

4. L. L. Alston, Breakdown Characteristics in Gases, High Voltage Technology, Oxford University Press, pp. 45-58, 1968.

5. M. J. Wison, D. A. Goerz, and R. D. Speer, LCR Bridge Measurements at Elevated Operating Levels, 1997 High Voltage Workshop. Newport Beach, LLNL Doc. UCRL-MI-125796 May 1997.

6. S. Sampayan and M. Buttram, Repetitive Spark Gap Switches, LLNL. Report UCRL-102624, 1990.

7. M. J. Wilson and D. A. Goerz, Compact High Voltage Structures, 11 th IEE International Pulsed Power Conference, Baltimore, MD, LLNL Doc. UCRL-JC-125862, June 1997. 


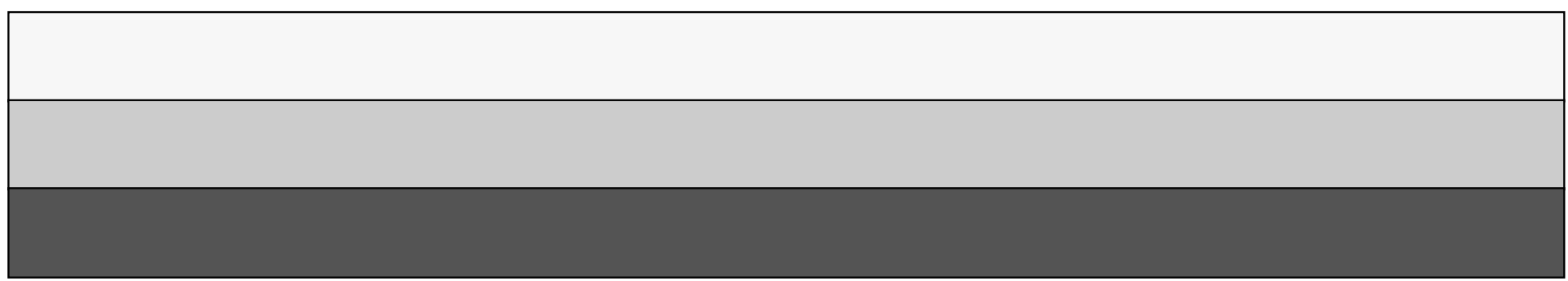

